\title{
Fracture Mechanics Approach to Splitting in Low Spring Index Cold Coiling Process
}

\author{
Y. Prawoto $\cdot$ S. Manville $\cdot$ T. Sakai $\cdot$ L. Lee $\cdot$ \\ M. Tanaka $\cdot$ T. Gnaupel-Herold
}

Submitted: 18 December 2018/Published online: 17 May 2019

(C) ASM International 2019

\begin{abstract}
This paper is an attempt to understand the coil splitting phenomena by means of fracture mechanics. The methods used combine the residual stress measurement with neutron and finite element analysis. The support of the metallurgical evaluation is used as evidence to justify the use of the fracture mechanics concept. Comparing coil springs manufactured at two different manufacturing lines, namely N1 and N6, residual stress distributions in three main directions were measured using neutron diffraction. The results of the residual stress measurement were then converted into the stress intensity factor to enable the analysis in fracture mechanics. The mixed-mode analysis of opening, Mode I, and in-plane shearing, Mode II, is used to solve the splitting problem. The discrepancy between the coil made at N1 and N6 was identified and taken into account in terms of the profile difference. Based on this difference, an FEA simulation was conducted. The results support the experimental finding, which is that the shape of the coil manufactured influences the pattern of the residual stress, which leads to different splitting behaviors. This simple analysis helps practitioners understand why, and how, some cold coiled products split after manufacturing. It is concluded that this very basic concept of fracture
\end{abstract}

Y. Prawoto $(\varangle) \cdot$ S. Manville $\cdot$ T. Sakai $\cdot$ L. Lee

NHK International Co, 46855 Magellan Dr, Novi, MI 48377,

USA

e-mail: yunan.prawoto@gmail.com

\section{Tanaka}

NASCO Spring USA, 3251 Nashville Road, Bowling Green, KY 42101, USA

T. Gnaupel-Herold

NIST Center For Neutron Research, 100 Bureau Dr,

Gaithersburg, MD 20899, USA mechanics can be used to establish the limit of the cold coiling process by evaluation of the mixed-mode stress intensity factor to the fracture toughness of the material.

Keywords Residual stress - Neutron diffraction · Cold forming $\cdot$ Stress intensity factor $\cdot J$-Integral

\section{Introduction}

Spring index is the ratio between the mean diameter of a spring and the wire diameter of a spring. It has been known that this proportion determines the strength of the spring, the stress induced on the spring, and the manufacturability of the spring.

By conventional manufacturing methods, typically a spring index up to 3.9 cannot be manufactured, while a spring index between 4 and 5 falls in the difficult to manufacture category due to too much stress on the tooling and higher possibility in cracking during the manufacturing process, resulting in higher cost to manufacture. A spring index in the range of 6-12 is the preferred choice for coil manufacturers. Above 12, tolerance becomes an issue and coil manufacturers typically cannot meet the drawing provided by the design engineers [1].

Meanwhile, the demand of weight reduction in the automotive industry forces suspension spring manufacturers to use higher-strength steel. The traditional approach in forming such materials is based on hot coiling of the wire at temperature higher than the $\mathrm{AC}_{3}$ line to increase material formability while the material is still in austenite form. This method has been used for decades and has been proven to minimize required forming forces. Recent development, however, is to manufacture the coil spring by 
cold forming. In the cold forming process, advantages include improved shape because heat treatments can be performed elsewhere prior to the spring being formed. In cold coiling, material is formed directly in its final condition, typically tempered martensite. Consequently, the coiling process becomes more critical because the formability of this high-strength martensitic steel is usually low compared to austenite in the case of hot coiling.

Nowadays, the high-strength steel used for suspension coil spring material is moving even further in the direction of much more high strength up to $2100 \mathrm{MPa}$, although in the market usually $1800 \mathrm{MPa}$ is about the limit. Even at this level, the cold forming of the wire can be extremely difficult, triggering manufacturing failure caused by the breakage of the spring and splitting. These types of problems for some manufacturers that use hot coiling could be troublesome. Similar problems in cold coiling are also reported in several other publications [2,3]. In their paper, Matejicek et al. [3] used neutron diffraction and found that the residual stress is mainly responsible for splitting.

This paper discusses a particular problem in the cold coiling process where the coil splits along the wire either soon after coiling or sometime between the coiling process and the end of the stress-relief annealing process. The approach used here concentrates on the effect of residual stress since cracking takes place after the coiling process is complete, similar to that of Matejicek et al.'s [3]. To do this, we mimic his approach combined with finite element method, metallurgy, and fracture mechanics. The approach of quantitative analysis is preferred here with the hope that this would initiate better research in understanding the phenomena.

\section{Theory}

To approach the problem, basic knowledge of fracture mechanics is used. The residual stress is converted into a stress intensity factor and subsequently used to analyze the splitting. In this case, Mode I and Mode II are used in the analysis simultaneously, instead of the $J$-Integral concept that is more suitable for softer materials [4]. Since the material is very hard and brittle, as it is discussed in Metallurgical evaluation section, the approach to use the stress intensity factor is fully justified. Recall that the stress intensity factor, $K$, is used in fracture mechanics to predict the stress state near the tip of a crack caused by a remote load or residual stresses. It is a theoretical idea applied to a homogeneous, linear elastic material and is useful for providing a failure criterion for brittle materials; it is a favorite technique in the discipline of damage tolerance. The value depends on sample geometry, the size and location of the crack, and the magnitude and modal distribution of loads on the material. The stress state near the crack

$\sigma_{i j}(r, \theta)=\frac{K}{\sqrt{2 \pi r}} f_{i j}(\theta)$

where $K$ is the stress intensity factor and $f_{i j}$ is a dimensionless quantity that varies with load and geometry

In our case, Mode I and Mode II, respectively, are

$K_{I}=\lim _{r \rightarrow 0} \sqrt{2 \pi r} \sigma_{y y}(r, 0)$

$K_{I I}=\lim _{r \rightarrow 0} \sqrt{2 \pi r} \tau_{x y}(r, 0)$

The failure criterion in this case is taken as

$K_{c} \leq \sqrt{K_{I}^{2}+K_{I I}^{2}}$

where $K_{c}$ is the material fracture toughness. This approach is believed to be much better and more suitable than the conventional failure criteria, such as Tresca or Von Mises failures $[5,6]$.

\section{Experiment}

Material selected was SAE 9254, due to its popularity in both cold coiling and hot coiling processes [7]. Two different coil springs, manufactured at two different coil machines, are used for this study. Figure 1 shows a typical coil machine for cold coiling process. The forming cycle varies from 6 to $10 \mathrm{~s}$, and the formed spring requires a simple setting stage without further heat treatments, except a stress-relief annealing. The machine is a numerical programmable system, consisting of wire feeder roll where the wire is straightened and fed from the bundle to the wire guide. The wire guide passes the wire to the first forming roll where the first coiling process takes place. The second forming roll and the pitch bar work synergistically to form the coil into desired shape. Both the pitch bar and the roll

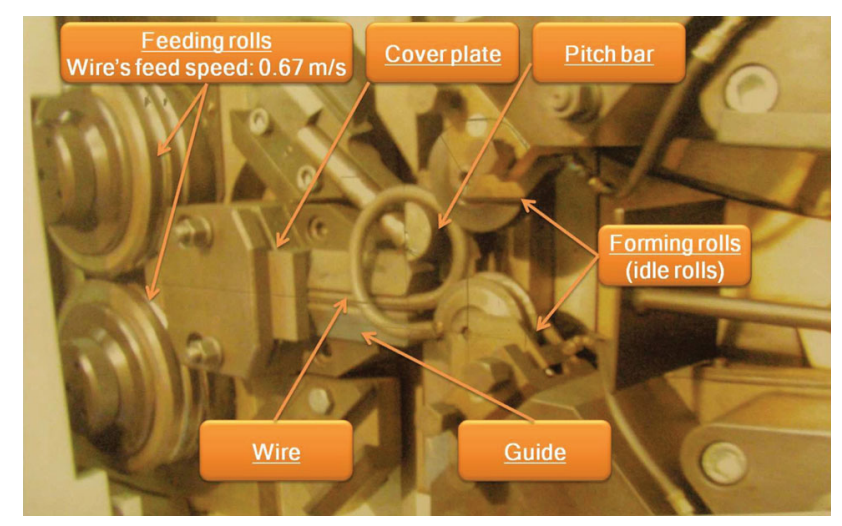

Fig. 1 Cold coiling machine 
are controlled by programs and servo systems. Here, the coil pitch and the diameter are shaped to the desired dimension. Once the coil forming is finished, the upper shear will move down to cut the wire. It is worth noting that shearing also introduces energy to the system that indirectly contributes to the initiation of the splitting.

The usage of two forming rolls allows reduction in the friction between the wire and the forming tools, and therefore, the required forming force is also reduced. After this, the coil is sent to the next process, which is stressrelief annealing. Residual stress remaining during coiling is mostly eliminated during this process. Occasionally, the coil splits after the coiling process. Figure 2 shows the representative appearance of such phenomena. It is the suspicion that this is due to excessive residual stress created during coiling. The evaluation items are limited to FEA simulations, neutron diffraction and $\mathrm{x}$-ray residual stress measurement, and metallurgical evaluation.

\section{FEA Simulations}

Figure 3 shows the initial setup of the model. The model mimics the real experiment, where the wire with a diameter of $14.9 \mathrm{~mm}$ is fed into the wire feeder and eventually shaped into a coil using Roller 1 and Roller 2. Both rollers
Fig. 2 Appearance of the splitting that takes place after coiling before stress-relief annealing. The figure also shows the concept for the usage of mixed mode
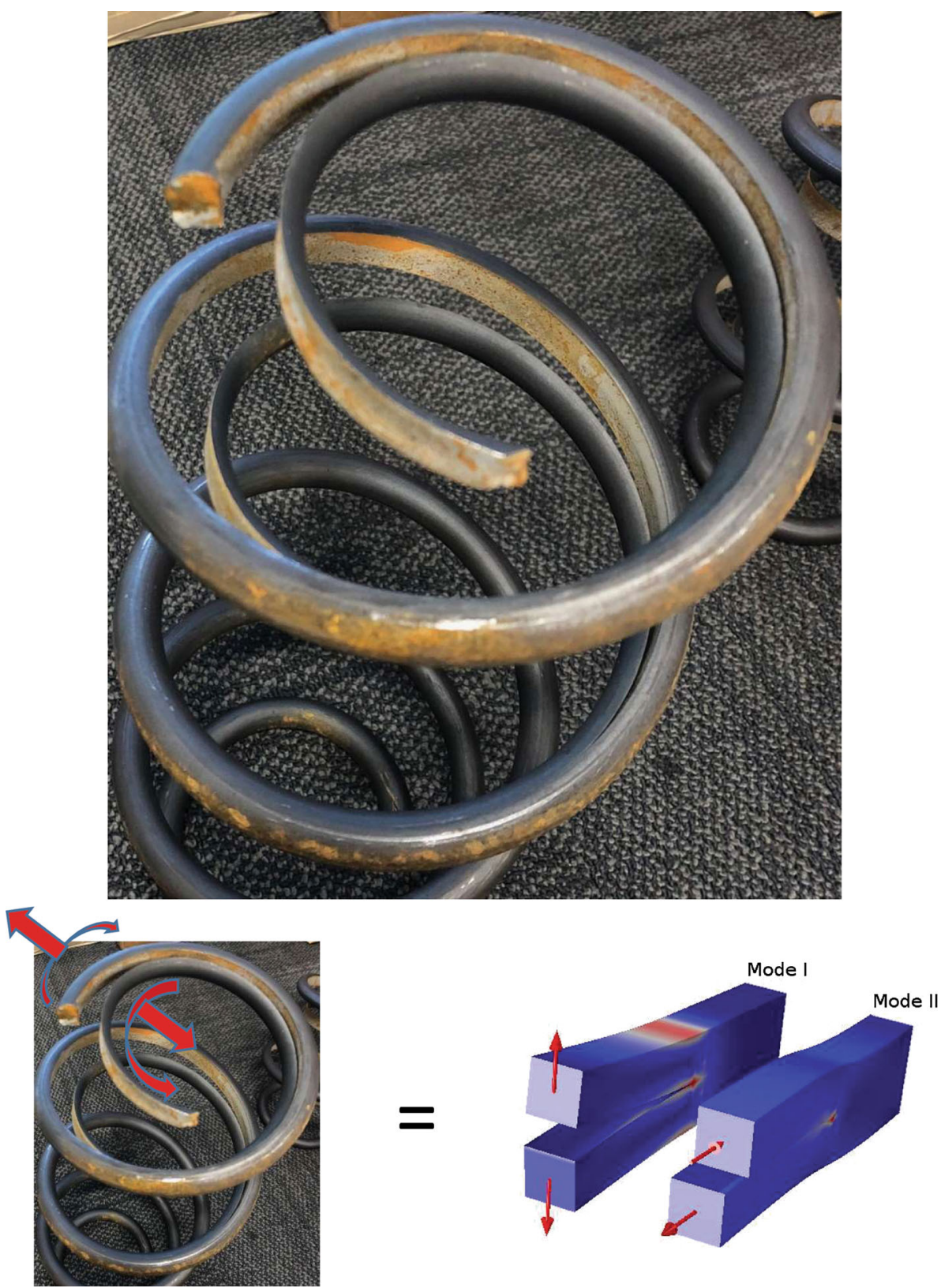


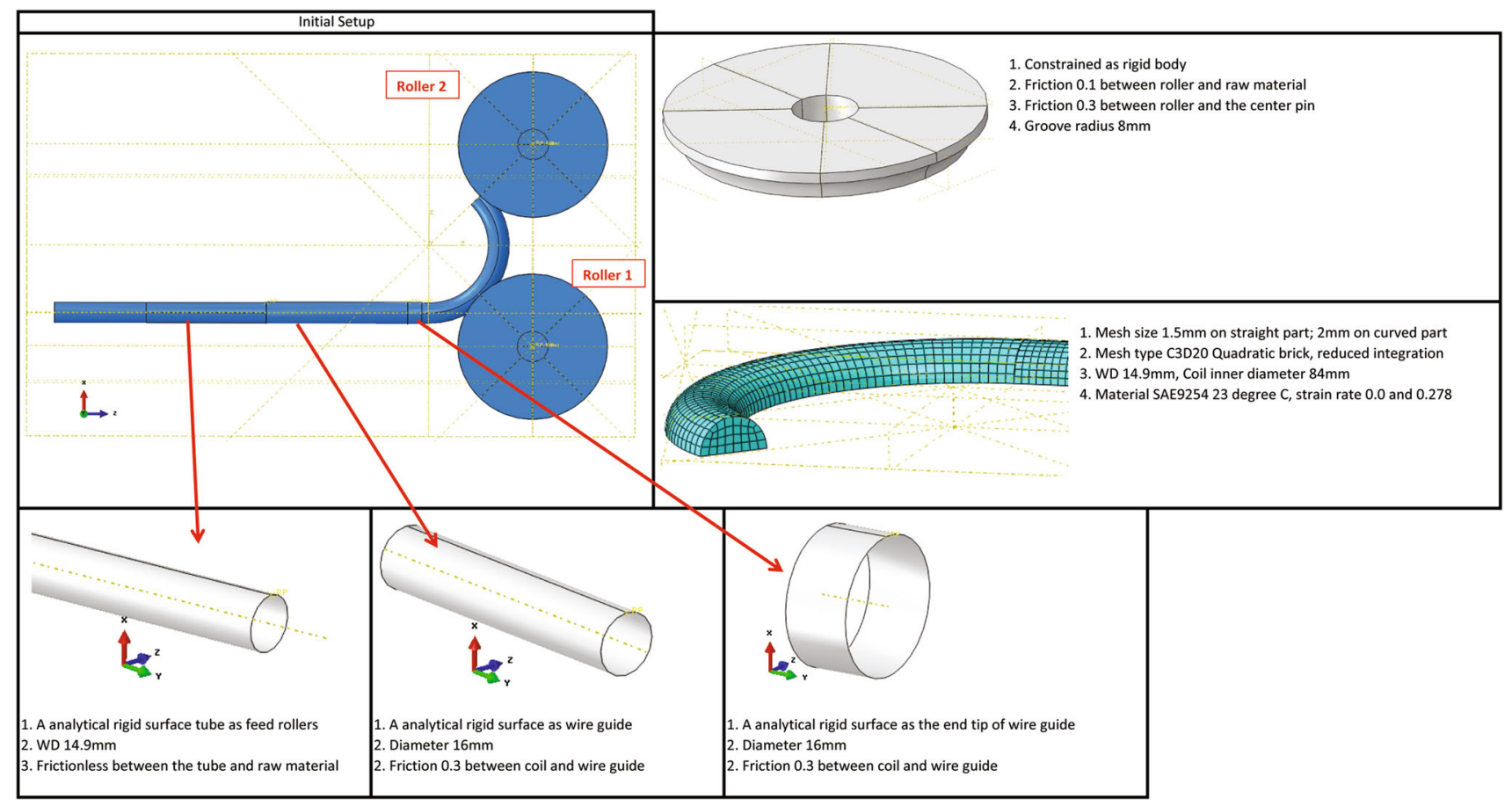

Fig. 3 Initial setup of FEA model

are constrained as rigid bodies having a 0.1 friction coefficient relative to the wire. The rollers can spin with respect to its center axles with a friction coefficient of 0.3 relative to the axles. The friction coefficient between the wire and the wire guide is also 0.3 . This variation of the friction coefficient is able to produce a similar situation with the experiment where the angular displacement at the surface of the roller is slower than wire displacement due to the wire being pushed.

In the initial setup, the tip of the wire is already coiled $135^{\circ}$. The simulation is started with pushing the tip of the opposite end so that plastic deformation takes place on the originally straight wire to form coil. For this particular analysis, a convergence test was performed and a mesh size of $1.5 \mathrm{~mm}$ at the straight part and that of $2 \mathrm{~mm}$ at the curved part were concluded to have converged results. The analysis used Abaqus ${ }^{\mathrm{TM} 1}$ with a meshing type of C3D20 Quadratic brick with reduced integration. The material constants used were to follow those of SAE9254 at $23{ }^{\circ} \mathrm{C}$ with the strain rate of 0.0 and 0.278 . The information from the drawing was used. Profiling the actual coil shapes obtained in experiment made it possible to differentiate the simulation of $\mathrm{N} 1$ and $\mathrm{N} 6$ coils. In this section, the only difference between N1 and N6 is the coil profiles. The coil profiles were measured experimentally.

\footnotetext{
${ }^{1}$ Mention of commercial products does not imply endorsement by the National Institute of Standards and Technology, nor does it imply that such products or services are necessarily the best available for the purpose.
}

In general, the procedure consists of two steps. The first step is to feed the wire until an addition of more than $180^{\circ}$ of new coil is formed. In this step, it simulates coil manufacturing where energy supplied to the system is used to plastically bend the wire, slip the wire to the roller, and to rotate the rollers. The first step is ended by stopping the displacement of the left end of the wire. This first step left the system in an elastic equilibrium of the wire giving compression to the roller. The second step is to move the rollers away from the wire leaving the wire in the coil shape. At this step, the spring back of the coil due to the removal of elastic compression experienced by the wire to the rollers takes place. Consequently, the coil shape is changed from the original shape obtained in step 1 . The simulation is completed after the second step.

The change from the straight wire to coil basically takes place in a mixture of compression and tension inside the system. Furthermore, the degree of the plastic deformation also varies significantly. As a result, the system consists of a variation of residual stress due to new equilibrium of the wire being in the shape of a coil. The analysis result is extracted as remaining stress in all elements. With some coordinate manipulations, the results are presented here. Figure 4 shows the result of the tangential residual stress, which is the residual stress in the wire direction. Y-axis values are given in units of (MPa); Xaxis values are dimensionless $(\mathrm{x} / \mathrm{d})$ with $\mathrm{x}$ as the radial position and $\mathrm{d}$ the diameter. It is like what we expect the longitudinal stress distribution to be, as the stress in this direction is the 
Fig. 4 Tangential (wire direction) residual stress distribution. Y-axis values are given in units of (MPa); $\mathrm{X}$-axis values are dimensionless $(\mathrm{x} / \mathrm{d})$ with $\mathrm{x}$ as the radial position and $\mathrm{d}$ the diameter

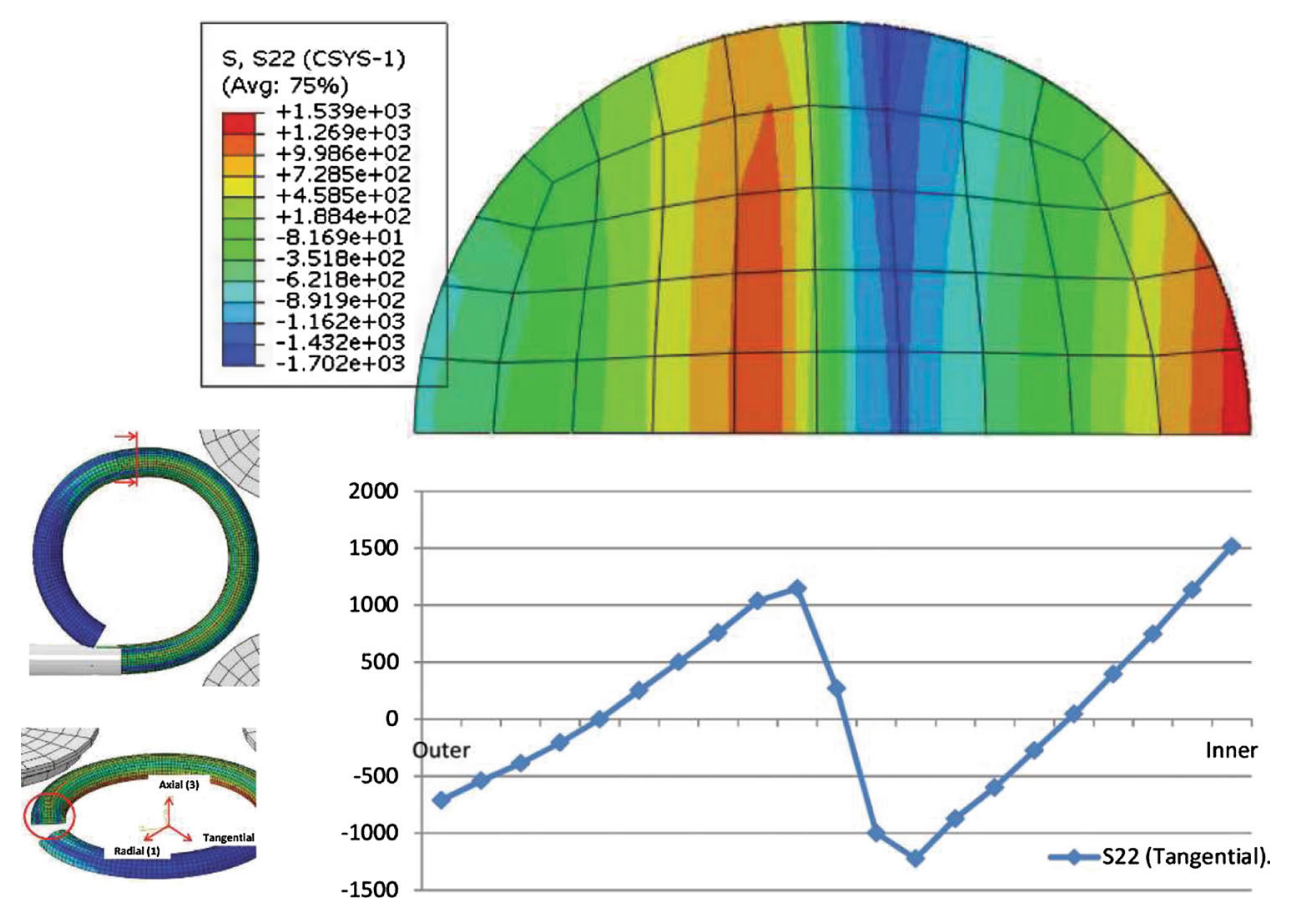

remaining stress of the applied bending moment in classical mechanics:

$\sigma_{T}=\frac{M y}{I}$

where $\sigma_{T}$ is the tangential/hoop stress, $M$ is the applied moment, $y$ is the distance from the neutral axis and $I$ is the moment of inertia of circular cross section, $\pi r^{4} / 4$. According to Eq 4, the applied stress due to the moment given during coiling would become tension at the outer diameter of the bending and compression at the inner. Figure 5 illustrates the estimate of tangential residual stress. In order to make the system in both force and moment balance, an imaginary negative moment is introduced. A similar concept can be used to comprehend the radial direction of stress, as shown in Fig. 6. In the case of stress in the radial direction, the problem becomes similar to that of a thick-walled cylinder problem where stress in the radial direction is formulated by:

$\sigma_{r}=\frac{E}{1-v^{2}}\left(\frac{\mathrm{d} u}{\mathrm{~d} r}+v \frac{u}{r}\right)$

where $\sigma_{r}$ is the radial stress. The term $\left(\frac{\mathrm{d} u}{\mathrm{~d} r}\right)$ is actually the radial strain, $\varepsilon_{r}$. Equation 5 for our system cannot be solved easily since they form partial differential equations that involve two constants that require two boundary conditions with a difference being too small to be even considered. This direction of stress is usually neglected. However, for this particular investigation, this stress is not neglected despite its small amount, a maximum about $50 \mathrm{MPa}$. This is far from the tangential stress value, which is above
$1000 \mathrm{MPa}$. The radial direction of residual stress here is computed because it relates directly to Mode I failure discussed in Eq 2a and eventually in Eq 3.

More significantly is the shear stress at the same location. The shear stress is related directly to Eq $2 b$, which is Mode II in fracture mechanics, and eventually to Eq 3. Figure 7 shows the distribution of the residual shear stress. This is the most important aspect in this research since Mode II is also factor that contributes to splitting along with Mode I, as it is shown in Eq 3. Figure 8 is understood by the concept of shear stress in beam classical mechanics:

$\tau_{T}=\frac{V}{I b} \int_{y 0}^{c} y \mathrm{~d} a$

where $\tau_{T}$ is the shear stress and $V$ is the applied shear load which in our case is $V=\frac{\mathrm{d} M}{\mathrm{~d} x}$. Recall that $M$ is the applied moment used in Eq 4, $y$ is the distance from the neutral axis, and $I$ is the moment of inertia of circular cross section, $\pi r^{4} / 4$, while $b$ is the width. The integral part would be in the form of first moment, which is the area of wire cross section. Similar to how Fig. 6 is established, one can establish illustration to estimate the distribution of the residual shear stress. While Fig. 3 until Fig. 7 describe the general analysis results, the discrepancy between $\mathrm{N} 1$ and N6 is shown in Fig. 8. In Fig. 8, the tangential/hoop residual stress of $\mathrm{N} 1$ is shown to be slightly larger than that of N6. Similar trends are also found on the radial direction and the shear stress. It is worth noting here that some of the results are not accurate since in principle the following concepts remain true: 

stresses at the wire; note that the imaginary moment only creates
Fig. 5 Illustration of tangential elastic stress
Fig. 6 Radial (coil radius direction) residual stress distribution. Here, this stress is related directly to Mode I of fracture mechanics. Y-axis values are given in units of $(\mathrm{MPa})$; $\mathrm{X}$-axis values are dimensionless $(\mathrm{x} / \mathrm{d})$ with $\mathrm{x}$ as the radial position and $\mathrm{d}$ the diameter
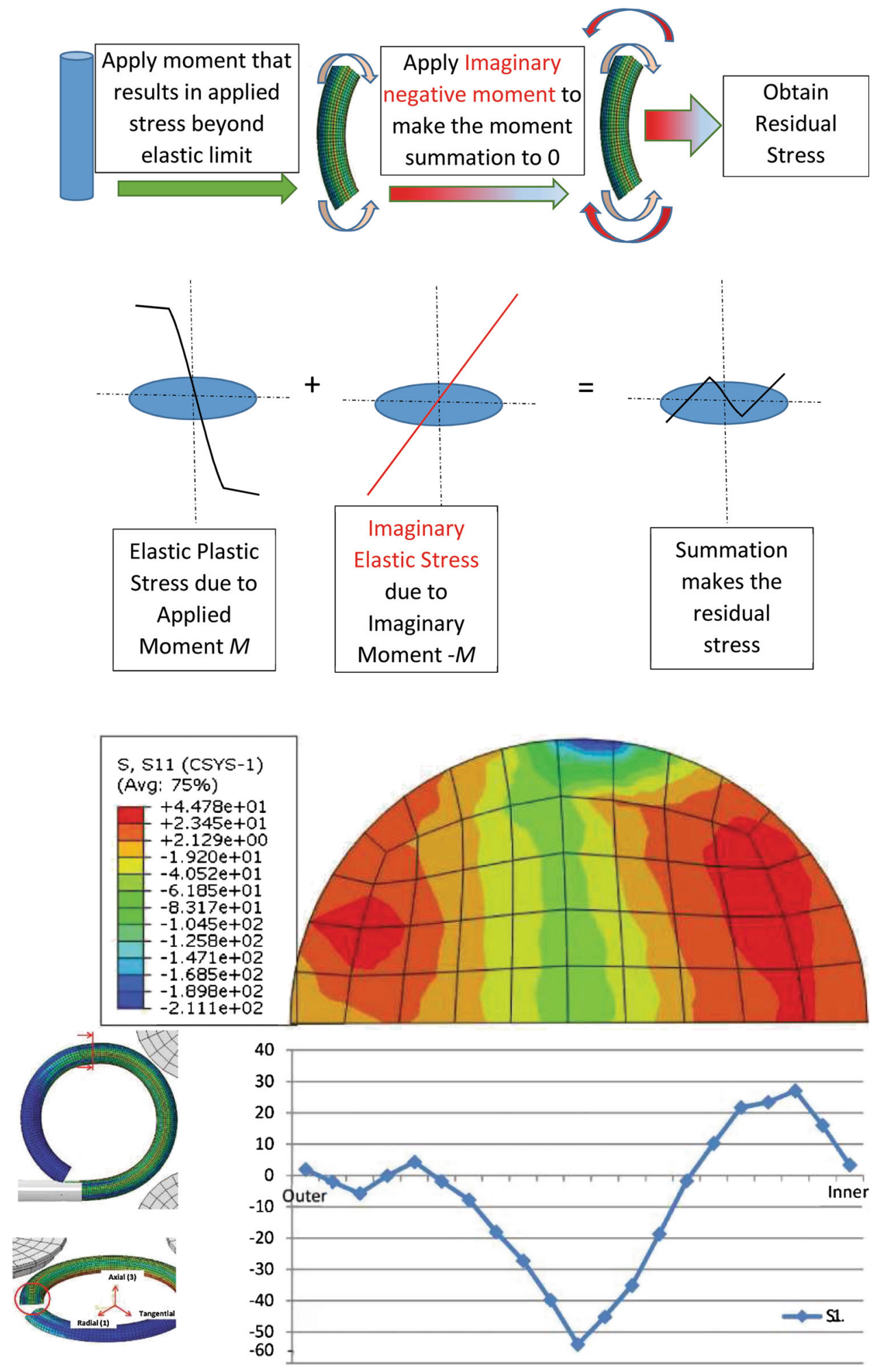

$\sum F=0$ and $\sum M=0$

(Eq 7)

Therefore, when using the results described in Fig. 8, one needs to be careful as they may not be accurate quantitatively in their numerical values, but rather should be taken qualitatively. In this research, the values of the residual stresses are converted into residual stress intensity factors, which enables us to make better explanation as to why the splitting happens and further as to why the N1 coil has higher probability to split than the N6 coil. 
Fig. 7 Shear (radial plane; tangential direction) residual stress distribution. Here, this stress is related directly to Mode II of fracture mechanics. Y-axis values are given in units of (MPa); $\mathrm{X}$-axis values are dimensionless $(\mathrm{x} / \mathrm{d})$ with $\mathrm{x}$ as the radial position and $d$ the diameter

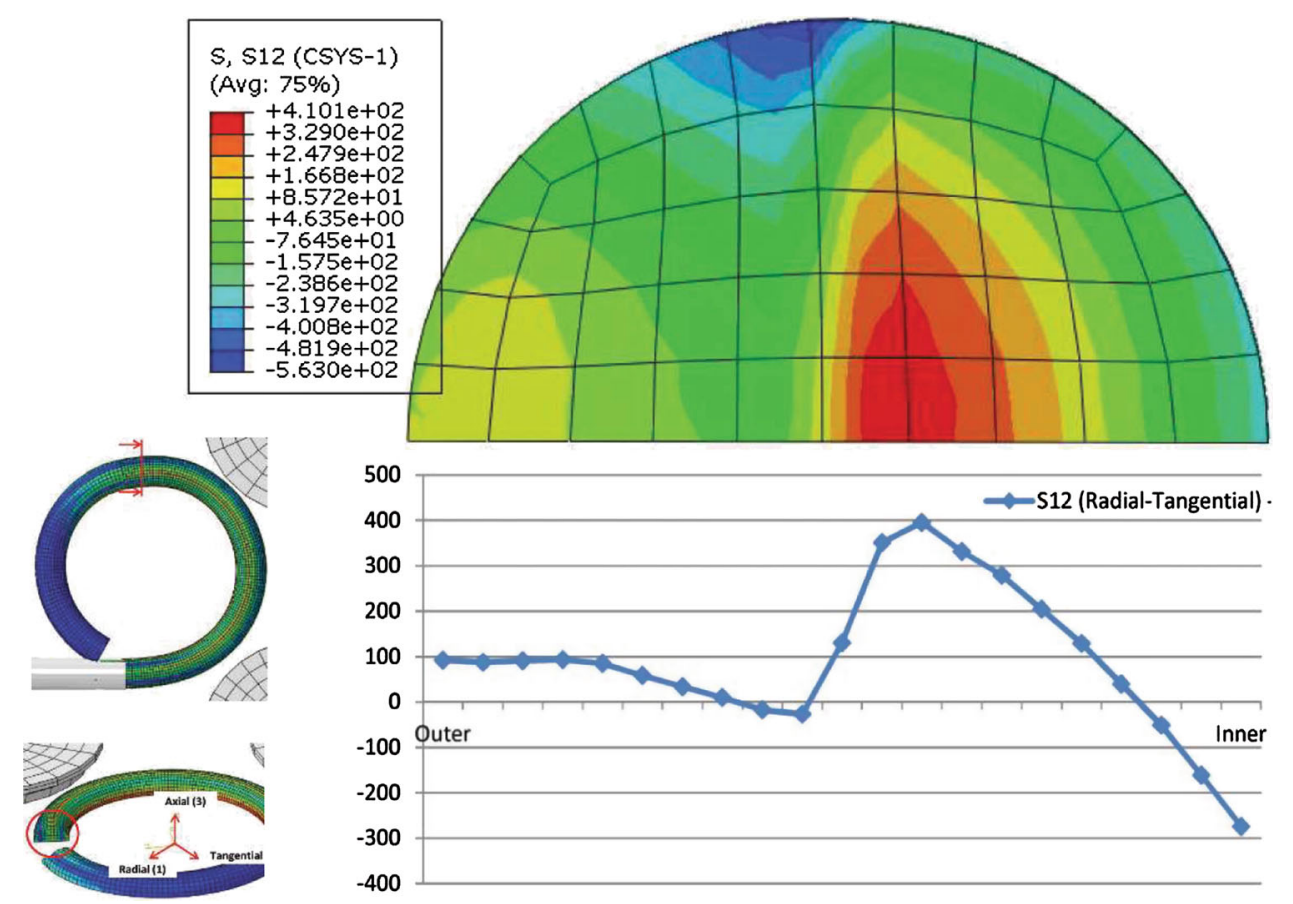

$\sigma_{33}=\frac{E}{(1+v)(1-2 v)}\left[(1-v) \varepsilon_{33}+v\left(\varepsilon_{11}+\varepsilon_{22}\right)\right]$

$(\mathrm{Eq} 10 \mathrm{c})$

The measurement of residual stress with neutron diffraction is based on measurements of changes in crystal lattice spacing, which manifests themselves as shifts in angular position of respective diffraction peaks, according to Bragg's law:

$n \cdot \lambda=2 d \sin \theta$

where $n$ is the reflection order, $\lambda$ is the radiation wavelength, $d$ is the plane spacing, and $\theta$ is the diffraction angle.

The strain can then be computed by:

$\varepsilon=\left(\frac{d-d_{0}}{d_{0}}\right)$

where $\varepsilon$ is the strain in a particular direction and $d$ and $d_{0}$ are the stressed and unstressed interplanar spacing, respectively.

The stress components can be calculated as:

$\sigma_{11}=\frac{E}{(1+v)(1-2 v)}\left[(1-v) \varepsilon_{11}+v\left(\varepsilon_{22}+\varepsilon_{33}\right)\right]$

(Eq 10a)

$\sigma_{22}=\frac{E}{(1+v)(1-2 v)}\left[(1-v) \varepsilon_{22}+v\left(\varepsilon_{11}+\varepsilon_{33}\right)\right]$

(Eq 10b)
In our case, $\sigma_{11}$ is the stress in tangential direction, while $\sigma_{22}$ is the stress in the radial direction, as shown in Fig. 9. The gage volume for this measurement was $1.5 \mathrm{~mm} \times 1.5 \mathrm{~mm} \times 1.5 \mathrm{~mm}$. Figure $10 \mathrm{a}$ and $\mathrm{b}$ shows the measurement results. The tendency of the residual stress measured by neutron diffraction is similar to that of the FEA computational results. However, the residual shear stress can only be calculated and not measured by neutron diffraction.

To compare the measurement results with the FEA results, one can pick the most obvious measurement results, which are tangential residual stress. In Fig. 8, the peak of the residual stress is about $1000-1100 \mathrm{MPa}$, while in Fig. 10a and b it is about 800-900 MPa. Recall that our gage volume for measurement was $1.5^{3}\left[\mathrm{~mm}^{3}\right]$, or $3.375 \mathrm{~mm}^{3}$. In this volume of the gage, using our material that has grain size of 10 , we average approximately 4.85 million prior austenite grains. Therefore, in this case, residual stress value is always an underestimation, because the gage size is much larger than the size of the peak. 

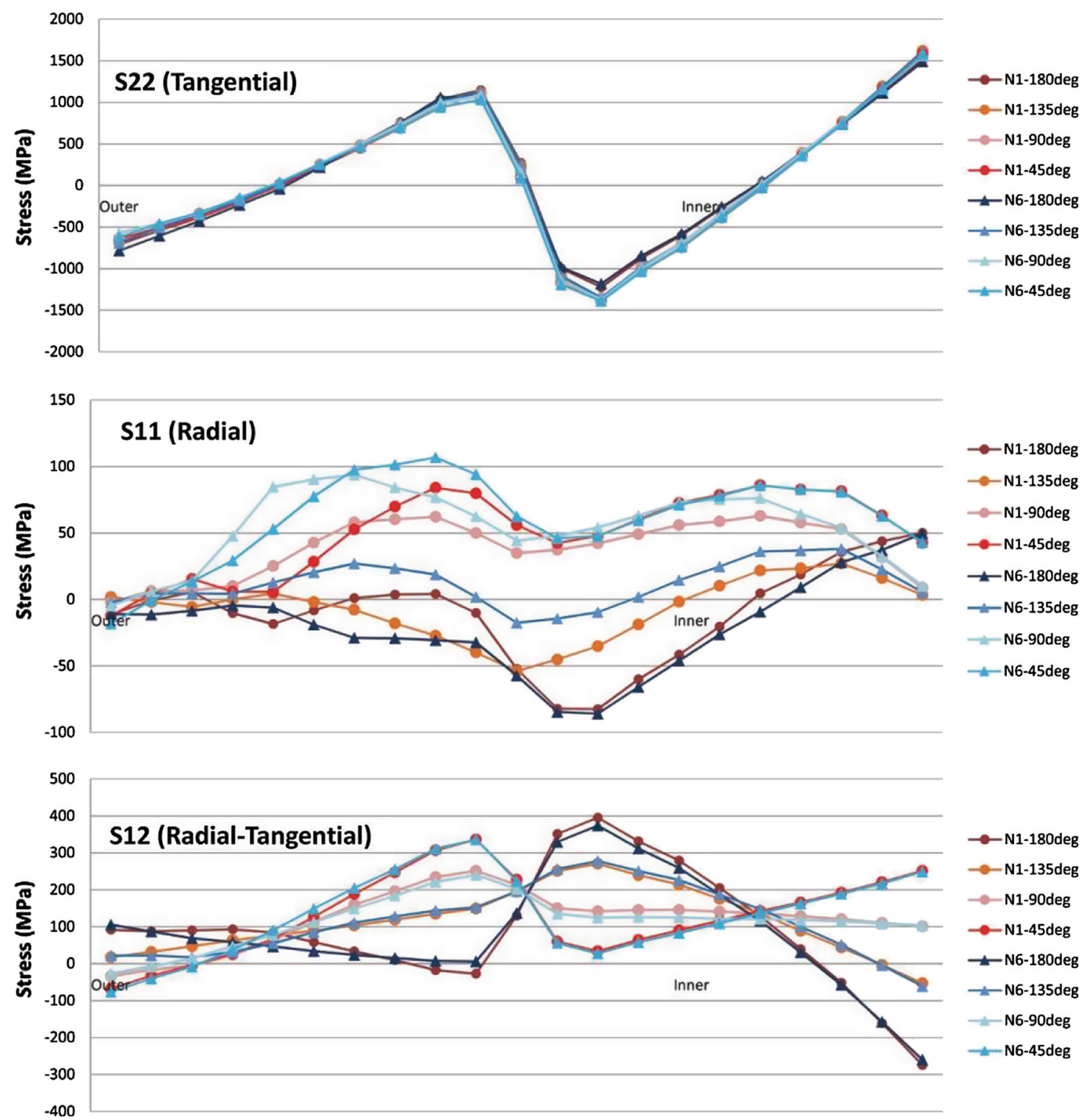

Fig. 8 Summary of the analysis results. The comparison here is based on the models constructed to match profiles of N1 and N6 coils

\section{Metallurgical Evaluation}

Metallurgical evaluation is focused on the tip of the cracks. On the samples manufactured at N1 and N6, approximately 200-mm-length coils were sectioned and mounted carefully into transparent lucite. The samples were subsequently ground and polished. During polishing, both samples split at a location almost identical with what happened to other coils that split after cold coiling. Figure 11 shows the appearance. The same figure also shows the mapping of microhardness. No significant difference between the two coils was found from this evaluation. The spectrum of the hardness of the N6 sample seems broader than that of N1 sample. However, this is very common discrepancy since the samples are not annealed.

With this, Fig. 11 shows the condition at the crack tips for both the N1 and N6 samples. The figure shows that the N1 sample has a straighter crack compared with the N6 sample. The N6 sample has many more crack branches than the N1 sample. This implies that the stress of N1 is higher than the stress in N6. Figure 12 shows the enlargement of the crack path at a selected location. This figure is used as a tool to determine which modes were involved in the cracking. One can see the tendency of the cracking mode to be mixed between Mode I and Mode II, as they are indicated by red arrows. In the figure, the red 
Fig. 9 Measurement orientation is to mimic the measurement of Matejicek et al.'s [3]. The lower diagram shows the coordinate and points of measurements

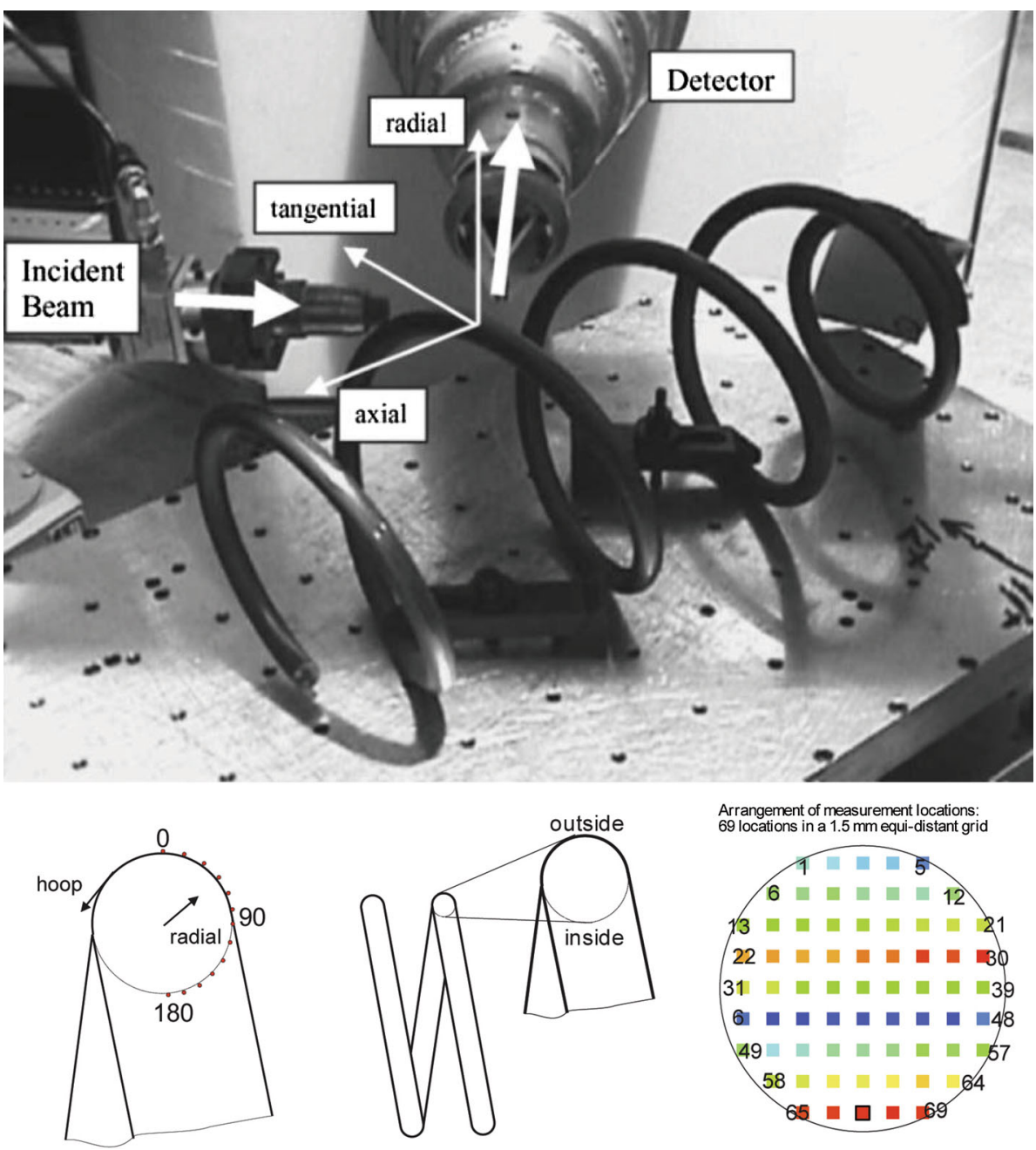

arrows show the vectors of translation from points that were originally adjacent. This proves that the cracking was indeed the combination of Mode I and Mode II. Regular proof of grain elongation could not be observed due to the sample being hardened. This fact justifies the use of the stress intensity factor concept rather than $J$-Integral concept.

\section{Discussion}

In this research, qualitatively one can get the idea that excessive residual stress caused the splitting to take place after the cold coiling process. However, to what extent the residual stress caused the splitting remains unexplainable, since classical mechanics only states that if the Von Mises stress is lower than the UTS, no splitting can ever take place. If the generalized concept is used, the maximum average stress would never crack the sample, given the fact that the residual stress value is not even $80 \%$ of the material's ultimate tensile strength.

In this research, the idea is to get an explanation of why the splitting takes place only with residual stress. To do that, the stress intensity factor is brought in. Furthermore, the concept of weight function is also adopted in converting the residual stress into residual stress intensity factor.

$K_{I}=\int_{0}^{a} \sigma^{R}(x) h_{I}(x, a) \mathrm{d} x$

and

$K_{I I}=\int_{0}^{a} \tau^{R}(x) h_{I I}(x, a) \mathrm{d} x$

where $\sigma^{R}(x)$ and $\tau^{R}(x)$ are the normal residual stress and the shear residual stress along the crack prospective line, respectively. $K_{I}$ and $K_{I I}$ are Mode I and Mode II stress intensity factors, respectively, and $h_{I}(x, a)$ and $h_{I I}(x, a)$ are the weight functions that depend solely on the geometry 
Fig. 10 (a) Neutron diffraction measurement results for spring N1. (b) Neutron diffraction measurement results for spring N6. Errorbars represent $1 \times$ sigma. $\mathrm{Y}$-axis values are given in units of (MPa); $X$-axis values are dimensionless $(\mathrm{x} / \mathrm{d})$ with $\mathrm{x}$ as the radial position and $d$ the diameter
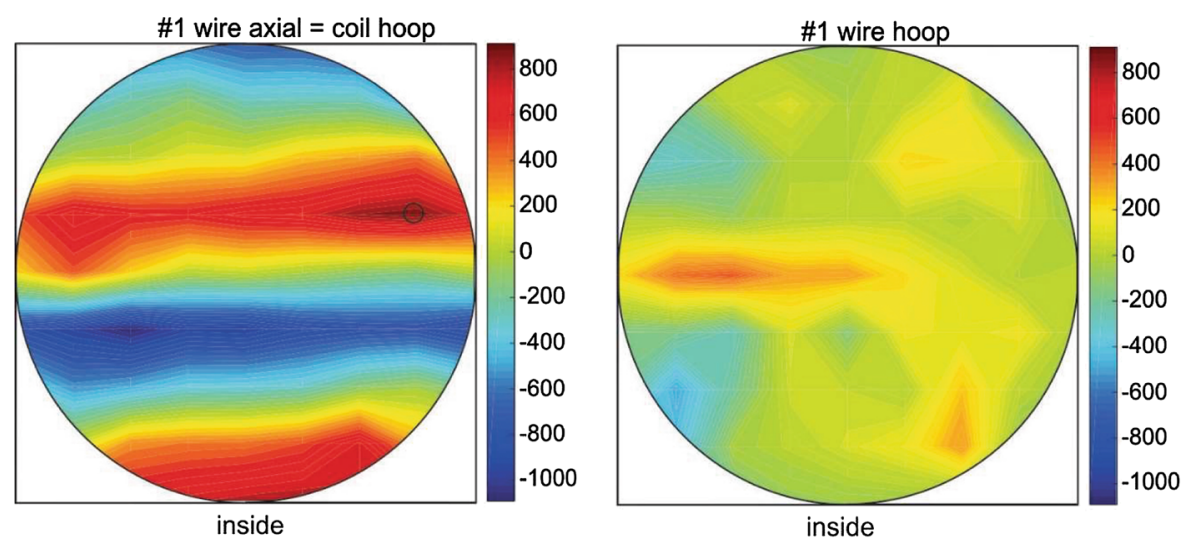

(a)
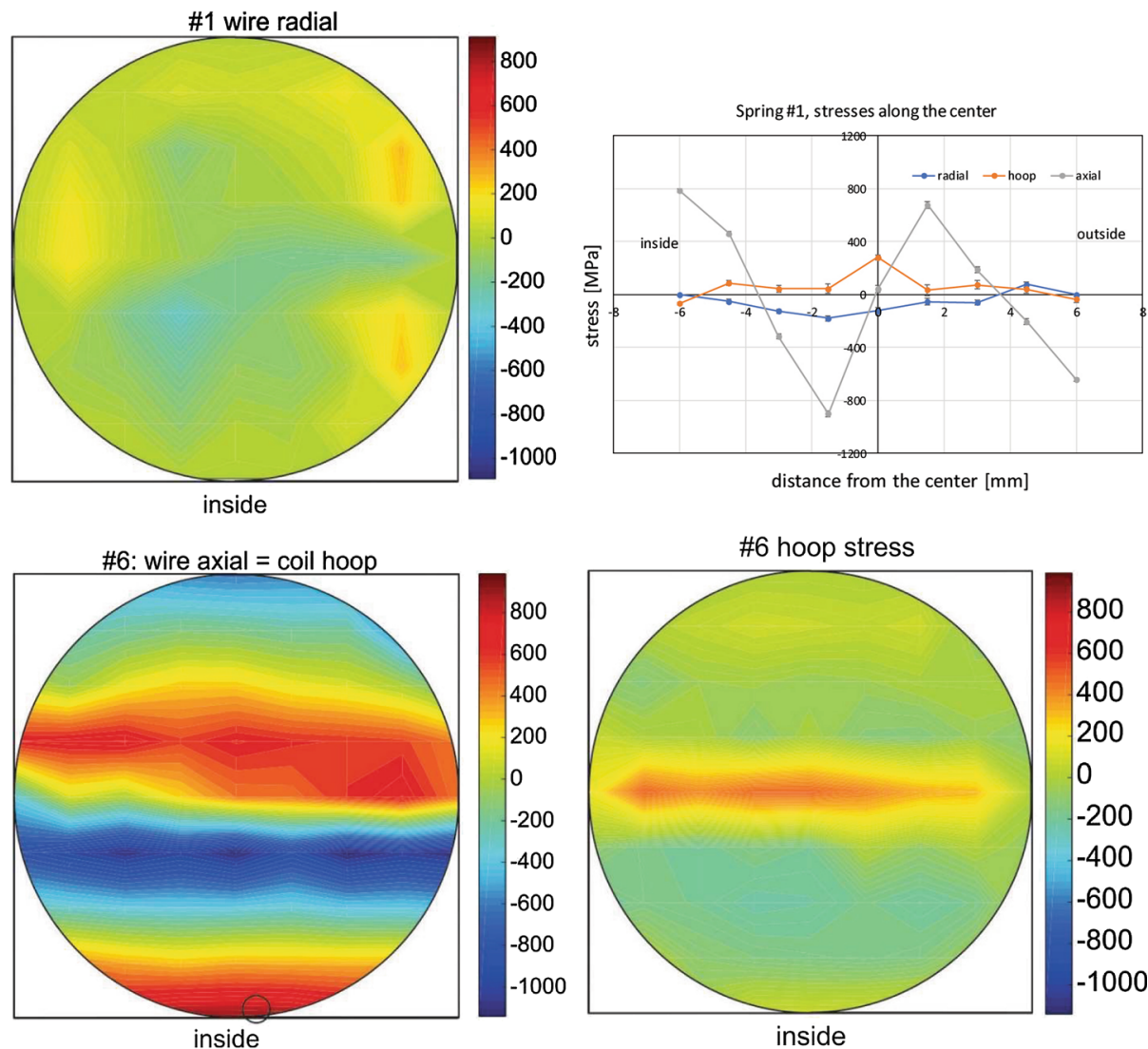

distance from the center $[\mathrm{mm}]$

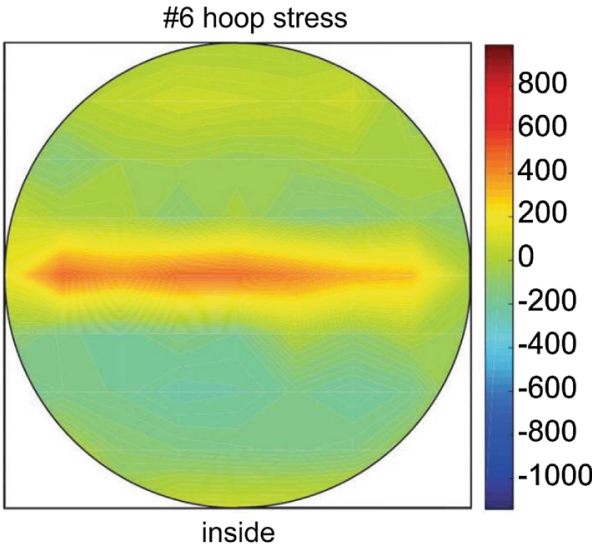

\#6 wire radial stress
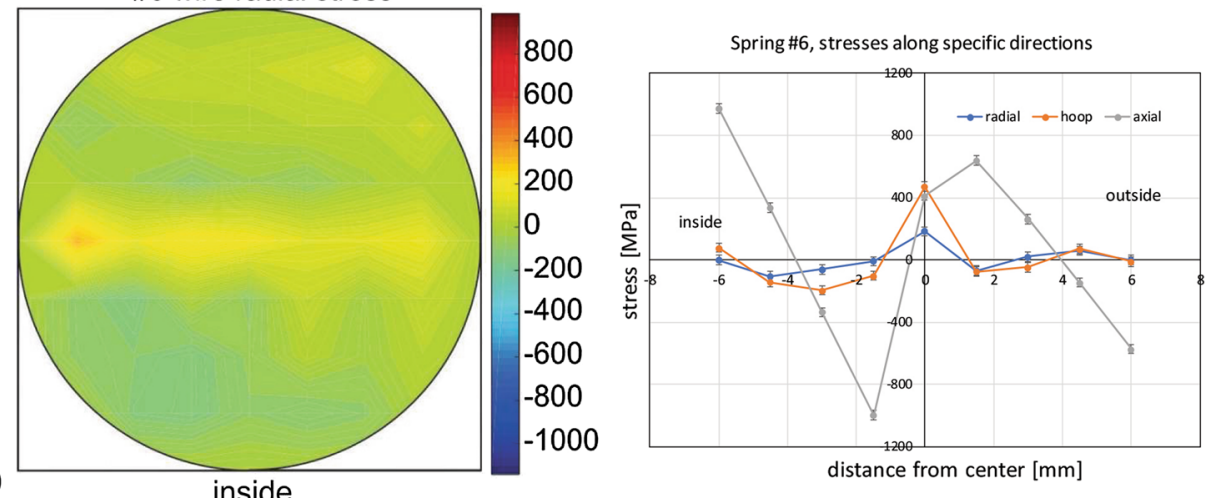
Fig. 11 Microhardness mapping on the samples along three different paths

\section{Sample N1}

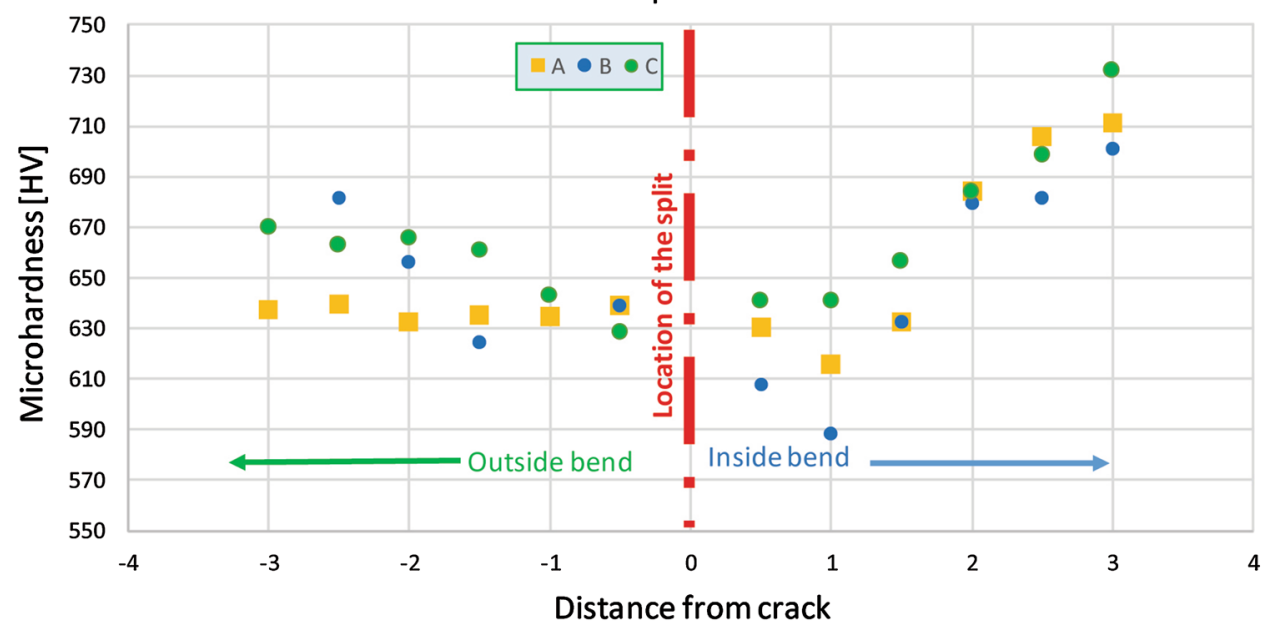

Sample N6

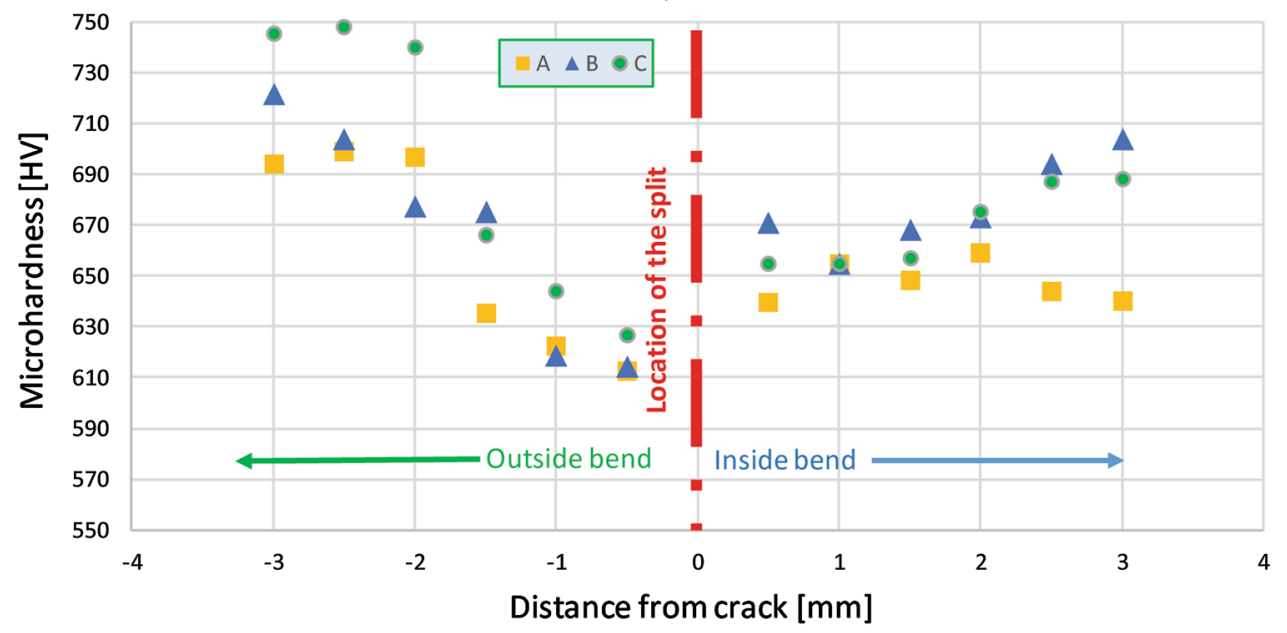

[8-10]. Generally, the value of the weight function is computable through:

$h(x, a)=\frac{H}{K(a)^{(1)}} \frac{\partial u^{(1)}(x, a)}{\partial a}$

$H$ is $E$ for plane stress condition and $\frac{E}{1-v^{2}}$ for plane strain condition. $K(a)^{(1)}$ and $u^{(1)}(x, a)$ are, respectively, the known stress intensity factor and the crack face displacement. To find those, the help of FEA was utilized. A model to mimic this was created, and subsequently, the stress intensity factor, $K^{(1)}$, is calculated and the displacement function $u^{(1)}$ was also obtained. For this purpose, the computation was via $J$-Integral and the following relation is used.

$J=K^{2} \frac{\left(1-v^{2}\right)}{E}$

To obtain the value of the parameters needed, analysis shown in Fig. 13 was performed. From this analysis, the correlation of the displacement behind the crack, the crack face displacement, $u^{(1)}(x, a)$, was obtained. At the same time, the corresponding $K(a)^{(1)}$ was also obtained. The 

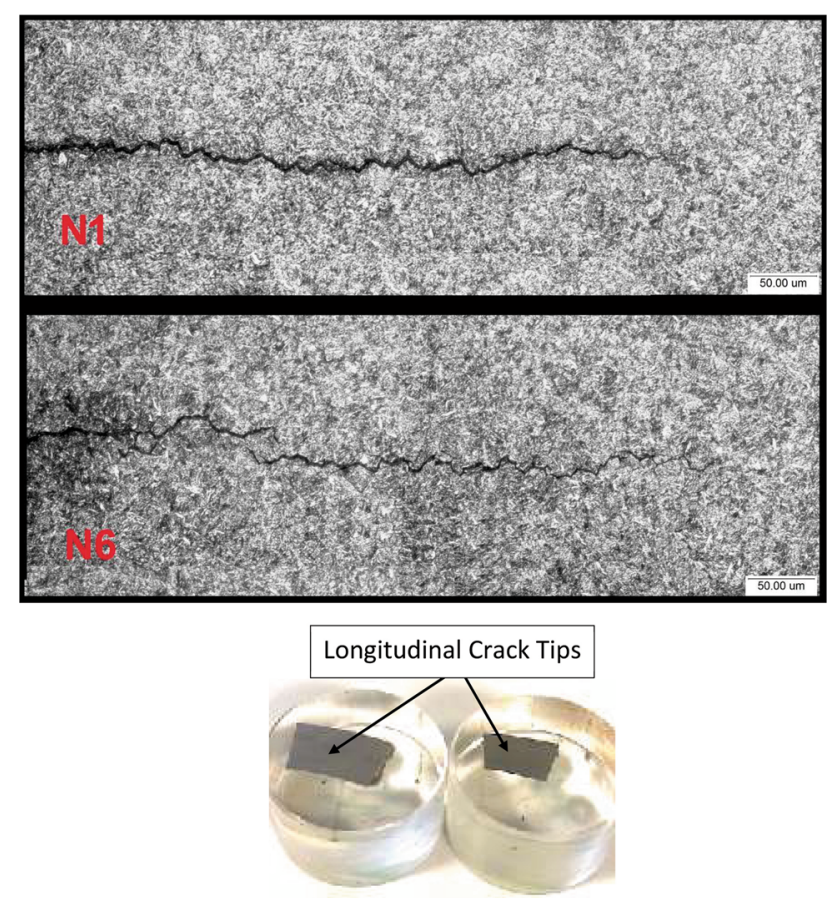

Fig. 12 Metallurgical evaluation at the crack tips. N6 sample shows more crack branching, which is an indication of less (applied) stress during the crack formation

analysis to simulate both Modes I and II was performed by giving dummy displacements of unity. Subsequently, the relation of the displacement versus stress intensity factor can be obtained in the four-degree polynomial for Mode I as:

$$
\begin{aligned}
h_{I}(x, a)= & \frac{H}{K(a)^{(1)}} 0.048+0.0008 a-0.0012 a^{2}-0.0846 x \\
& +0.08 a x
\end{aligned}
$$

and for Mode II as:

$$
\begin{aligned}
h_{I I}(x, a)= & \frac{H}{K(a)^{(1)}} 0.0828-0.0188 a+0.0021 a^{2}-0.007 x \\
& +0.0066 a x
\end{aligned}
$$

The above empirical equations were obtained by analytical program, Mathematica ${ }^{\mathrm{TM}}$ - three-dimensional curve fitting into a three-degree polynomial followed by partial differential with respect to $h_{I}(x, a)$. Recall that the above equations are related directly to Eqs $11 \mathrm{a}$ and $11 \mathrm{~b}$.

The idea of bringing the metallurgical concept into the solid mechanics world is always fascinating. In this research, one can see that both Mode I and Mode II contributed to the splitting, as shown in Fig. 13. Furthermore,
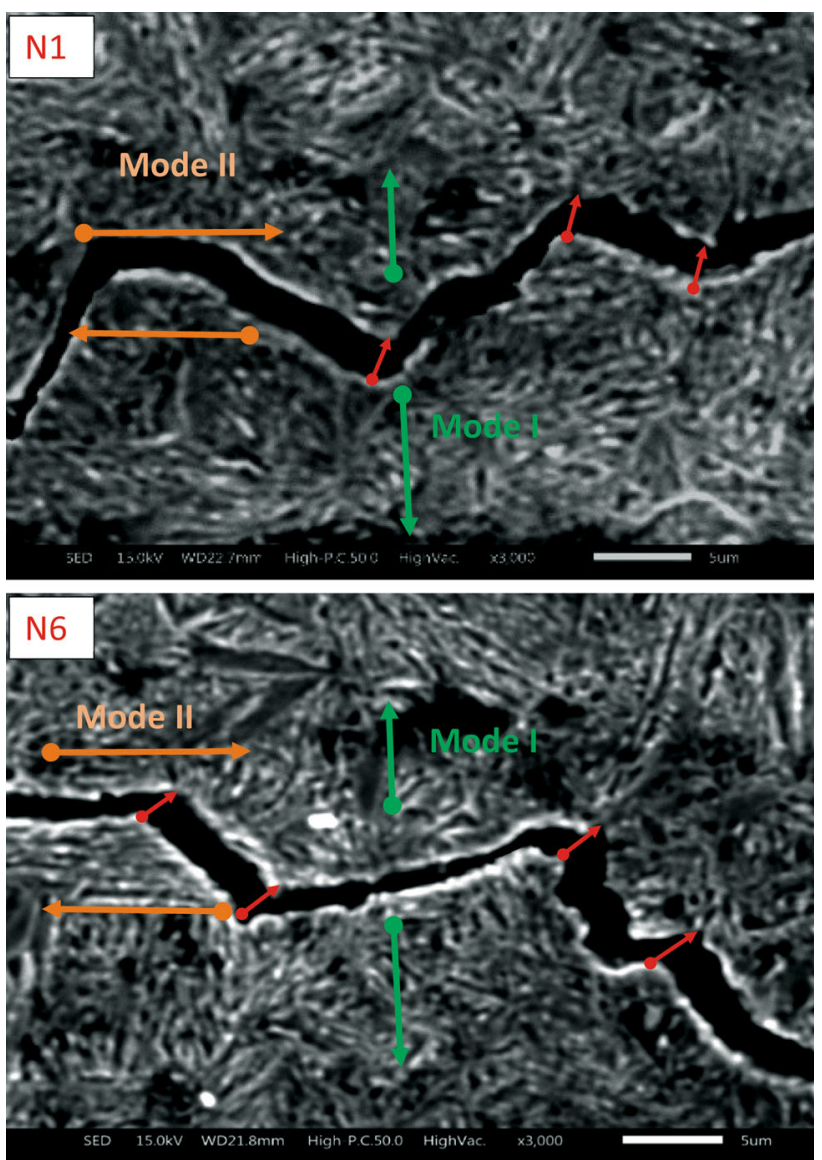

Fig. 13 Metallurgical evaluation at selected locations. The appearance here is to confirm that the cracks are indeed influenced by both Mode I (opening) and Mode II (in-plane shear). The red arrows indicate that the translation vector is clearly a combination of Mode I and Mode II (Color figure online)

if the red arrow in the corresponding figure can be used as a vector for the fracture surface creation and separation, vector algebraic addition law should be applicable. Therefore, at the crack length of $8 \mathrm{~cm}$ our combined stress intensity factor becomes:

$K=\sqrt{K_{I}^{2}+K_{I I}^{2}}$

where $K_{I}$ and $K_{I I}$, respectively, can be calculated using the weight functions and FEA analysis of $K(8)_{I}^{(1)}=22,918$ and $K(8)_{I I}^{(1)}=3103$,

$K_{I}=\int_{0}^{8} \frac{E}{\left(1-v^{2}\right) 22,918}(-0.02+0.556 x) \sigma^{R}(x) \mathrm{d} x$

(Eq 16a)

and 
$K_{I I}=\int_{0}^{8} \frac{E}{\left(1-v^{2}\right) 3,103}(0.198+0.043 x) \tau^{R}(x) \mathrm{d} x$

(Eq 16b)

Knowing the material's Young modulus and Poisson's ratio, combined with $\sigma^{R}(x)$ and $\tau^{R}(x)$ from the neutron diffraction measurement and FEA modeling, Eqs 16a and $16 \mathrm{~b}$ can be calculated to become:

$K_{I}=\left.\frac{202,815}{20,855}\left(-0.6 x+8.34 x^{2}\right)\right|_{0} ^{8}=5144$

$K_{I I}=\left.\frac{202,815}{2,823}\left(79.2 x+8.60 x^{2}\right)\right|_{0} ^{8}=85,063$

$K=85,218$

Note that the above equations were calculated by considering the results that at the crack prospective line, the value of $\sigma^{R}(x)$ is $30 \mathrm{MPa}$ and $\tau^{R}(x)$ is $400 \mathrm{MPa}$ constant, while the Young's modulus $E$ is $202.815 \mathrm{GPa}$ and Poisson's ratio is 0.3 . Equations $17 \mathrm{a}$ and $17 \mathrm{~b}$ clearly show that the influence of the shearing is indeed much larger than that of normal stress. It is worth noting that the shear stress value can also be obtained by derivation of normal stress in the longitudinal direction. In doing the calculation, the help of Abaqus was also utilized here (Fig. 14).

After the unit conversion, Eq 18 can be directly compared with experimental fracture toughness. Here, the value of in SI unit $K=85.2 \mathrm{MPa} \sqrt{\mathrm{m}}$. This can be considered as a critical value because if the material used has fracture toughness lower than this value, e.g., high hardness, the material would be more prone to the splitting. The same material that has higher toughness, e.g., low hardness, would therefore be less prone to the splitting.

\section{Conclusion}

Springs manufactured at two different coil machines were selected for this study. Fracture mechanics theory was used to understand the phenomena. The splitting in this case
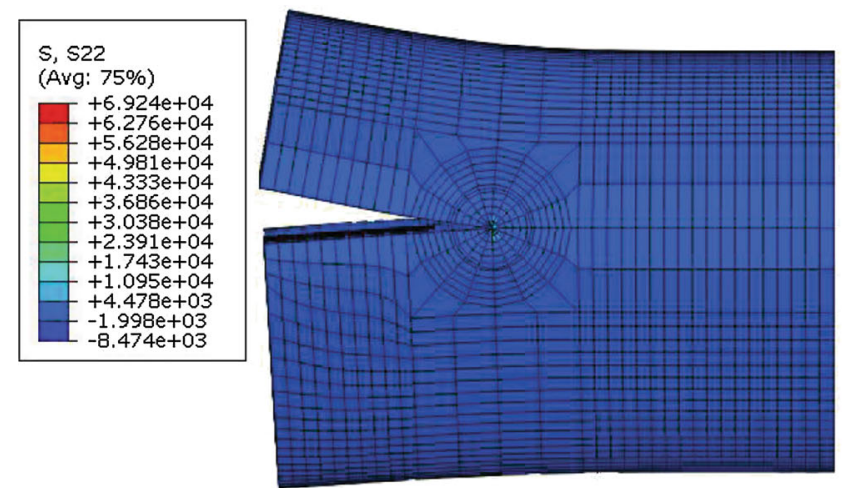

Mode I
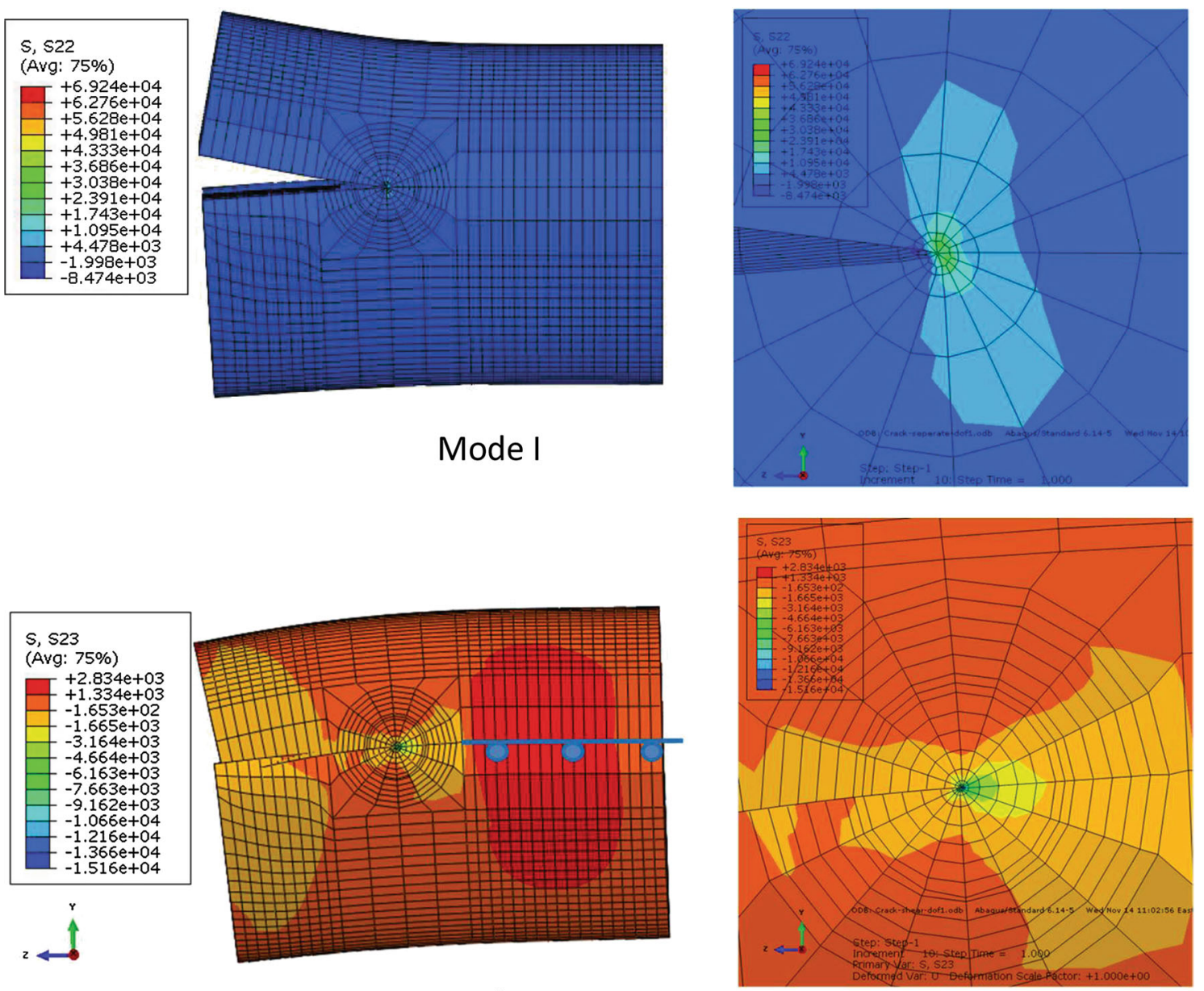

\section{Mode II}

Fig. 14 FEA model for the stress intensity calculation. The values of stress intensity factor are taken by the averaging of five contour values in front of the crack 
took place in the laboratory several days after manufacturing. Based on the crack tip evaluation, it was concluded that the cause for the splitting was due to normal stress acting to separate fracture surface and in-plane shear stresses acting synergistically. Here, metallurgy was used as a quantitative method to justify the introduction of mixed-mode fracture mechanics. The fracture mechanics concept was subsequently used to establish a critical boundary value between non-propagating or propagating cracks. It was shown that this boundary corresponds to fracture toughness value.

\section{References}

1. P. R. N. Childs, Springs. Mechanical Design Engineering Handbook (2014). https://doi.org/10.1016/b978-0-08-097759-1. 00015-0

2. B. Guido, M. Manuel, Experimental and numerical analysis of the cold forming process of automotive suspension springs. (Verlag Meisenbach GmbH, Bamberg/Germany, 2011), pp. 1-18. Retrieved December, 2018, from https://www.umformtechnik. net/binary_data/2343577_springforming_berti_monti_utfscience. pdf\&sa=U\&ved=2ahUKEwjgpe 2 Jg57iAhUMKa0KHZ0fBu4QFj AAegQIBBAB\&usg=AOvVaw2oo6MCitLCjOAZfF2tH1vM
3. J. Matejicek, P.C. Brand, A.R. Drews, A. Krause, C. Lowe-Ma, Residual stresses in cold-coiled helical compression springs for automotive suspensions measured by neutron diffraction. Mater. Sci. Eng. A 367, 306-311 (2004)

4. Y. Prawoto, I.H. Onn, Application of $J$-integral concept on blister coating problem. Eng. Fract. Mech. 92, 114-125 (2012)

5. Y.J. Chao, Ultimate strength and failure mechanism of resistance spot weld subjected to tensile, shear, or combined tensile/shear loads. J. Eng. Mater. Technol. 125, 125 (2003)

6. R.T. Qu, Z.J. Zhang, P. Zhang, Z.Q. Liu, Z.F. Zhang, Generalized energy failure criterion. Sci. Rep. 6, 1-8 (2016)

7. L. Vilela Costa, J.R. Gonçalves Carneiro, R. Pinto Coelho Catalão, O.K. Ribas, P. Brito, Residual stress gradients in AISI 9254 steel springs submitted to shot peening and heat treatment for increased fatigue resistance. Adv. Mater. Res. 996, 749-754 (2014)

8. T. Fett, M. Tilscher, D. Munz, Weight functions for cracks near the interface of a bimaterial joint and application to thermal stresses. Eng. Fract. Mech. 56, 87-100 (1997)

9. T. Fett, Stress intensity factors and weight function for a void with an annular crack. Int. J. Fract. 67, R41-R47 (1994)

10. H.E. Coules, G.C.M. Horne, K. Abburi Venkata, T. Pirling, The effects of residual stress on elastic-plastic fracture propagation and stability. Mater. Des. 143, 131-140 (2018)

Publisher's Note Springer Nature remains neutral with regard to jurisdictional claims in published maps and institutional affiliations. 